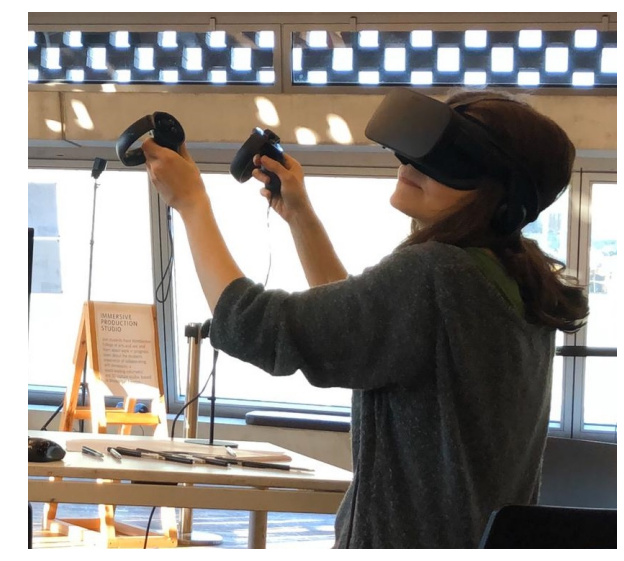

Figure 1: This image shows a participant training interactive machine learning system by performing a movement during a workshop.

There are many forms of complex movement interaction that are not well supported by current technologies, such as embodied movements that are more intricate and performative. As movement interaction in immersive media gains popularity, we aim to address the demand for easy-to-use tools and ideation approaches that enables the design of body based interaction. This project works with immersive media creators and movement practitioners in the context of in-the-wild research, in order to understand how interactive machine learning can be used to create better movement interaction ideologies in creative applications, performance and games.

\title{
Movement interaction design for immersive media using interactive machine learning
}

\section{Nicola Plant}

Goldsmiths, University of London, UK n.plant@gold.ac.uk

\section{Ruth Gibson}

Coventry University, UK

ruth.gibson@coventry.ac.uk

\section{Carlos Gonzalez Diaz \\ University of York, UK \\ cgd506@york.ac.uk}

\section{Bruno Martelli}

Studio Gibson/Martelli, London, UK bruno@gibsonmartelli.com

\section{Michael Zbyszyński}

Goldsmiths, University of London, UK

m.zbyszynski@gold.ac.uk

\author{
Rebecca Fiebrink \\ University of the Arts London, UK \\ r.fiebrink@arts.ac.uk
}

\section{Marco Gillies}

Goldsmiths, University of London, UK m.gillies@gold.ac.uk

\section{Clarice Hilton}

Goldsmiths, University of London, UK

c.hilton@gold.ac.uk

\section{Phoenix Perry}

University of the Arts London, UK

phoenix.perry@arts.ac.uk

\footnotetext{
Permission to make digital or hard copies of part or all of this work for personal or classroom use is granted without fee provided that copies are not made or distributed for profit or commercial advantage and that copies bear this notice and the full citation on the first page. Copyrights for third-party components of this work must be honored. For all other uses, contact the owner/author(s)

MOCO '20, July 15-17, 2020, Jersey City/ Virtual, NJ, USA

( 2020 Copyright held by the owner/author(s).

ACM ISBN 978-1-4503-7505-4/20/07.

https://doi.org/10.1145/3401956.3404252
} 


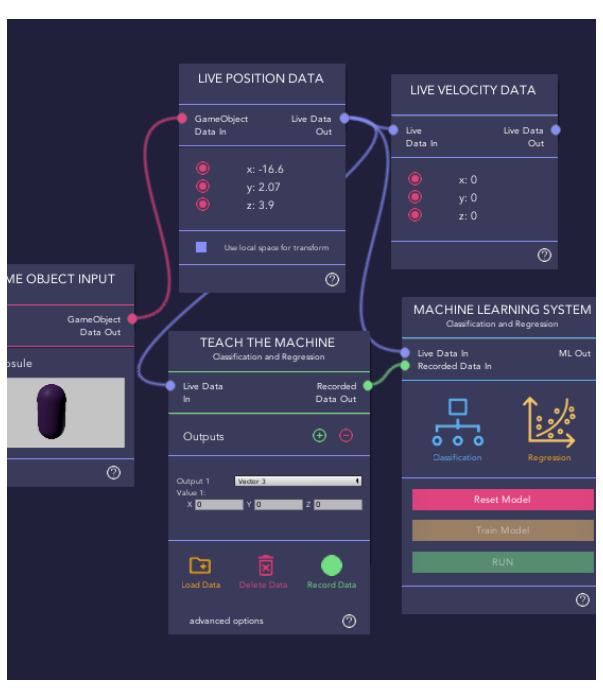

Figure 2: This image shows a section of the node based graph that allows users to configure and train interactive machine learning models using the InteractML tool.

During the workshop, participants will design movement interaction techniques and implement them using the tool InteractML [1], a plug-in for Unity 3D software. The tool is being developed to support users that do not have a background in computer programming to be able to train and configure the graph system to recognise complex movements. The workshops will provide feedback on how to improve the tool and refine working processes when designing movement interactivity for immersive media

\section{ABSTRACT}

Interactive Machine Learning is a promising approach for designing movement interaction because it allows developers to capture complex movements by simply performing them. We introduce a new tool being developed to make embodied interaction design faster, adaptable and accessible to developers of varying experience and background. Using the tool, we conduct workshops with creative practitioners and developers to explore techniques that equip users with embodied ideation design strategies encouraging full body interaction for immersive media.

\section{CCS CONCEPTS}

- Human-centered computing $\rightarrow$ Systems and tools for interaction design; Gestural input;

\section{KEYWORDS}

movement interaction; machine learning; immersive media, interaction design, virtual reality

\section{ACM Reference Format:}

Nicola Plant, Rebecca Fiebrink, Ruth Gibson, Marco Gillies, Carlos Gonzalez Diaz, Clarice Hilton, Bruno Martelli, Phoenix Perry, and Michael Zbyszyński. 2020. Movement interaction design for immersive media using interactive machine learning. In 7th International Conference on Movement and Computing (MOCO '20), July 15-17, 2020, Jersey City/ Virtual, NJ, USA. ACM, New York, NY, USA, 2 pages. https://doi.org/10.1145/3401956.3404252

\section{WORKSHOPS USING INTERACTML}

The workshop presented here will be online, interacting with participants virtually to design and implement their movement interaction designs over video conferencing. The workshop is based on two techniques. The first is embodied sketching: which explores new ways of designing movement interaction through "bodystorming" and "sketching" [3, 4]. If we are to carry on this embodied approach to design through to the implementation phase, we need to continue to use our body. Thus, our second technique, Interactive Machine Learning [2] uses an iterative design process allowing for rapid prototyping and refinement by performing body movements using the InteractML tool.

\section{REFERENCES}

[1] Carlos Gonzalez Diaz, Phoenix Perry, and Rebecca Fiebrink. 2019. Interactive Machine Learning for More Expressive Game Interactions. In 2019 IEEE Conference on Games (CoG). IEEE, London, United Kingdom, 1-2.

[2] Marco Gillies. 2019. Understanding the Role of Interactive Machine Learning in Movement Interaction Design. ACM Transactions on Computer-Human Interaction 26, 1 (Feb. 2019), 1-34.

[3] Kristina Höök. 2018. Designing with the Body - Somaesthetic Interaction Design. In Anais Estendidos do XVII Simpósio Brasileiro de Fatores Humanos em Sistemas Computacionais (IHC). Sociedade Brasileira de Computação (SBC).

[4] Elena Márquez Segura, Laia Turmo Vidal, Asreen Rostami, and Annika Waern. 2016. Embodied Sketching. In Proceedings of the 2016 CHI Conference on Human Factors in Computing Systems. ACM, San Jose California USA, 6014-6027. 